\title{
LOTVS: a global collection of permanent vegetation plots
}

Marta Gaia Sperandii ${ }^{1}$, Francesco de Bello ${ }^{1,2}$, Enrique Valencia ${ }^{3}$, Lars Götzenberger ${ }^{4,5}$, Manuele Bazzichetto $^{1}$, Thomas Galland ${ }^{2}$, Anna E-Vojtkó ${ }^{2,5}$, Luisa Conti ${ }^{6,5}$, Peter B. Adler ${ }^{7}$, Hannah Buckley ${ }^{8}$, Jiř́ Danihelka ${ }^{9,4}$, Nicola J. Day ${ }^{10}$, Jürgen Dengler ${ }^{11,12,13}$, David J. Eldridge ${ }^{14}$, Marc Estiarte ${ }^{15,16}$, Ricardo García-González $^{17}$, Eric Garnier ${ }^{18}$, Daniel Gómez-García ${ }^{17}$, Lauren Hallett ${ }^{19}$, Susan Harrison ${ }^{20}$, Tomas Herben $^{4,21}$, Ricardo Ibáñez ${ }^{22}$, Anke Jentsch ${ }^{23}$, Norbert Juergens ${ }^{24}$, Miklós Kertész ${ }^{25}$, Duncan M. $\mathrm{Kimuyu}^{26,27}$, Katja Klumpp ${ }^{28}$, Mike Le Duc ${ }^{29}$, Frédérique Louault ${ }^{28}$, Rob H. Marrs ${ }^{29}$, Gábor Ónodi ${ }^{25}$, Robin J. Pakeman ${ }^{30}$, Meelis Pärtel ${ }^{31}$, Begoña Peco ${ }^{32}$, Josep Peñuelas ${ }^{15,16}$, Marta Rueda ${ }^{33}$, Wolfgang $\mathrm{Schmidt}^{34}$, Ute Schmiedel ${ }^{24}$, Martin Schuetz ${ }^{35}$, Hana Skalova ${ }^{4}$, Petr Šmilauer ${ }^{36}$, Marie Šmilauerová ${ }^{2}$, Christian Smit ${ }^{37}$, Ming-Hua Song ${ }^{38}$, Martin Stock $^{39}$, James Val ${ }^{14}$, Vigdis Vandvik ${ }^{40}$, Karsten Wesche $^{13,41,42}$, Susan K. Wiser ${ }^{43}$, Ben A. Woodcock ${ }^{44}$, Truman P. Young ${ }^{45,27}$, Fei-Hai Yu ${ }^{46}$, Martin Zobel $^{31}$, Jan Lepš ${ }^{2}$.

\section{Affiliations:}

${ }^{1}$ Centro de Investigaciones sobre Desertificación (CSIC-UV-GV), 46113, Valencia, Spain.

${ }^{2}$ Department of Botany, Faculty of Science, University of South Bohemia, 37005, České Budějovice, Czech Republic.

${ }^{3}$ Departamento de Biología y Geología, Física y Química Inorgánica, Escuela Superior de Ciencias Experimentales y Tecnología, Universidad Rey Juan Carlos, 28933, Móstoles, Spain.

${ }^{4}$ Institute of Botany of the Czech Academy of Sciences, 25243, Průhonice, Czech Republic.

${ }^{5}$ Institute of Botany, Czech Academy of Sciences, Třeboň, Czech Republic.

${ }^{6}$ Faculty of Environmental Sciences, Czech University of Life Sciences Prague, Praha-Suchdol, Czech Republic.

${ }^{7}$ Department of Wildland Resources and the Ecology Center, Utah State University, 84322, Logan, UT, USA.

${ }^{8}$ School of Science, Auckland University of Technology, Auckland, New Zealand.

${ }^{9}$ Department of Botany and Zoology, Faculty of Science, Masaryk University, 61137, Brno, Czech Republic.

${ }^{10}$ School of Biological Sciences, Victoria University of Wellington, Wellington, New Zealand.

${ }^{11}$ Vegetation Ecology Group, Institute of Natural Resource Sciences (IUNR), Zurich University of Applied Sciences (ZHAW), Wädenswil, Switzerland.

${ }^{12}$ Plant Ecology Group, Bayreuth Center for Ecology and Environmental Research (BayCEER), University of Bayreuth, Bayreuth, Germany.

${ }^{13}$ German Centre for Integrative Biodiversity Research (iDiv) Halle-Jena-Leipzig, 04103, Leipzig, Germany. 
${ }^{14}$ Biological, Earth and Environmental Sciences, University of New South Wales, 2052, Sydney, Australia.

${ }^{15}$ Centre for Ecological Research and Forestry Applications (CREAF), 08193, Cerdanyola del Vallès, Catalonia, Spain.

${ }^{16}$ CSIC, Global Ecology Unit CREAF-CSIC-UAB, Bellaterra, Catalonia, Spain.

${ }^{17}$ Instituto Pirenaico de Ecología (IPE-CSIC), 22700, Jaca-Zaragoza, Spain.

${ }^{18}$ Center in Ecology and Evolutionary Ecology (CEFE), French National Centre for Scientific Research (CNRS), Univ Montpellier, École pratique des Hautes Études (EPHE), Research Institute for Development (IRD), 34293, Montpellier, France.

${ }^{19}$ Environmental Studies Program and Department of Biology, University of Oregon, Eugene, Oregon, 97403 USA

${ }^{20}$ Department of Environmental Science and Policy, University of California, 95616, Davis, CA, USA.

${ }^{21}$ Department of Botany, Charles University, Benátská 2, 12801 Praha 2, Czech Republic.

${ }^{22}$ Department of Environmental Biology, University of Navarra, 31008, Pamplona, Spain.

${ }^{23}$ Department of Disturbance Ecology, Bayreuth Center of Ecology and Environmental Research (BayCEER), University of Bayreuth, 95447, Bayreuth, Germany.

${ }^{24}$ Research Unit Biodiversity, Evolution \& Ecology (BEE) of Plants, Institute of Plant Science and Microbiology, University of Hamburg, 22609, Germany.

${ }^{25}$ Institute of Ecology and Botany, Centre for Ecological Research, Hungarian Academy of Sciences, 2163, Vácrátót, Hungary.

${ }^{26}$ Department of Natural Resources, Karatina University, Karatina, Kenya.

${ }^{27}$ Mpala Research Centre, Nanyuki, Kenya.

${ }^{28}$ Université Clermont Auvergne, French National Institute for Agriculture, Food, and Environment (INRAE), VetAgro Sup, UMR Ecosystème Prairial, 63000, Clermont-Ferrand, France.

${ }^{29}$ School of Environmental Sciences, University of Liverpool, L69 3GP, Liverpool, UK.

${ }^{30}$ The James Hutton Institute, Craigiebuckler, AB15 8QH, Aberdeen, UK.

${ }^{31}$ Department of Botany, Institute of Ecology and Earth Sciences, University of Tartu, 51005, Tartu, Estonia.

${ }^{32}$ Terrestrial Ecology Group (TEG), Department of Ecology, Institute for Biodiversity and Global Change, Autonomous University of Madrid, 28049, Madrid, Spain.

${ }^{33}$ Department of Plant Biology and Ecology, Universidad de Sevilla, Sevilla, Spain.

${ }^{34}$ Department of Silviculture and Forest Ecology of the Temperate Zones, University of Göttingen, 37077, Göttingen, Germany.

${ }^{35}$ Community Ecology, Swiss Federal Institute for Forest, Snow and Landscape Research (WSL), 8903, Birmensdorf, Switzerland.

${ }^{36}$ Department of Ecosystem Biology, Faculty of Science, University of South Bohemia, 37005, České Budějovice, Czech Republic. 
${ }^{37}$ Conservation Ecology Group, Groningen Institute for Evolutionary Life Sciences, 11103, Groningen, The Netherlands.

${ }^{38}$ Laboratory of Ecosystem Network Observation and Modelling, Institute of Geographic Sciences and Natural Resources Research, Chinese Academy of Sciences, 100101, Beijing, China.

${ }^{39}$ Wadden Sea National Park of Schleswig-Holstein, 25832, Tönning, Germany.

${ }^{40}$ Department of Biological Sciences and Bjerknes Centre for Climate Research, University of Bergen, 5020, Bergen, Norway.

${ }^{41}$ Botany Department, Senckenberg Natural History Museum Görlitz, Görlitz, Germany.

${ }^{42}$ International Institute Zittau, Technische Universität Dresden, Dresden, Germany.

${ }^{43}$ Manaaki Whenua - Landcare Research, 7640, Lincoln, New Zealand.

${ }^{44}$ UK Centre for Ecology \& Hydrology, Crowmarsh Gifford, OX10 8BB, Wallingford, Oxfordshire, UK.

${ }^{45}$ Department of Plant Sciences, University of California, Davis, USA.

${ }^{46}$ Institute of Wetland Ecology \& Clone Ecology / Zhejiang Provincial Key Laboratory of Plant Evolutionary Ecology and Conservation, Taizhou University, 318000, Taizhou, China.

* Correspondence:

Marta Gaia Sperandii, Centro de Investigaciones sobre Desertificación (CSIC-UV-GV), Valencia, Spain

ORCID: https://orcid.org/0000-0002-2507-5928

Email: marta.sperandii@ext.uv.es 


\begin{abstract}
Analysing temporal patterns in plant communities is extremely important to quantify the extent and the consequences of ecological changes, especially considering the current biodiversity crisis. Long-term data collected through the regular sampling of permanent plots represent the most accurate resource to study ecological succession, analyse the stability of a community over time and understand the mechanisms driving vegetation change. We hereby present the LOng-Term Vegetation Sampling (LOTVS) initiative, a global collection of vegetation time-series derived from the regular monitoring of vascular plants in permanent plots. With 79 datasets from five continents and 7789 vegetation timeseries monitored for at least six years and mostly on an annual basis, LOTVS possibly represents the largest collection of temporally fine-grained vegetation time-series derived from permanent plots and made accessible to the research community. As such, it has an outstanding potential to support innovative research in the fields of vegetation science, plant ecology and temporal ecology.
\end{abstract}

Keywords: permanent plots; time-series; plant communities; vegetation; plant diversity; global scale; temporal analysis; ecological succession; ecosystem stability; ecoinformatics.

\title{
1. Background
}

3 Anthropogenic changes are severely impacting our ecosystems (Bradshaw et al. 2021). The rate of

4 species loss has now exceeded background extinction rates (Pimm et al. 2014), leading many scientists

5 to claim a sixth mass extinction (Pereira, Navarro, \& Martins, 2012; Ceballos et al. 2015). At the same

6 time, a considerable proportion of natural habitats has been lost (Convention on Biological Diversity

7 2020) and a number of ecosystem functions and services are seriously at risk (IPBES 2019).

9 The analysis of time-based patterns in biological communities, especially when focused on primary producers like plants, represents an opportunity to quantify the extent and the consequences of such changes in biodiversity (Dornelas et al. 2014; Gonzalez et al. 2016; Blowes et al. 2019). This research field has potential for: i) unravelling the mechanisms that drive and maintain biodiversity over time (Jones et al. 2017; Hillebrand et al. 2018); ii) shedding light on how external drivers (e.g. global changes) affect community dynamics in natural habitats (Bernhardt-Römermann et al. 2015; Newbold et al. 2015) and iii) assessing relationships between community stability over time and the delivery of ecosystem services (Isbell et al. 2018). Reliable answers to these questions can only be provided by drawing upon ecological data collected at several points in time using consistent sampling procedures. For plant communities, long-term data collected by regularly sampling permanent plots probably constitute the most precise approach to detect temporal changes at the local scale (Bakker et al. 1996; 
field, permanent plots prevent relocation bias, i.e. the error derived from trying to find the original plot location. This bias is inherent in vegetation resurveys (Verheyen et al. 2018). Second, the repeated collection of vegetation data from permanent plots provides broad benefits to our understanding of vegetation change, including the means to track detailed successional trajectories, monitor species interactions over time and assess the stability of the community as a whole. For this reason, permanent plots have been listed among the six most important developments in vegetation science over the past three decades (Chytrý et al. 2019).

In recent decades, vegetation science has benefited from the development and maintenance of large vegetation databases (Dengler et al. 2011). Historical vegetation relevés performed by early vegetation ecologists, together with recent vegetation plot data stemming from regional, but also national or continental research and survey projects, have been carefully assembled and digitally archived in the context of centralized initiatives (Chytrý et al. 2016; Wiser 2016; Bruelheide et al. 2019; Sabatini et al. 2021). Such global collections of vegetation plot data are essential to investigate macroecological patterns and provide spatially meaningful answers to global issues, i.e. to effectively perform globalscale biodiversity research. In this context, a comparable effort specifically aimed at assembling and maintaining global databases built on time-series of vegetation data is urgently needed to lay a common ground for future studies focusing on i) providing global estimates of changes in plant diversity trends over time; ii) monitoring the conservation status of natural habitats over time or iii) assessing the stability of ecosystem functions and services. To the best of our knowledge, the BioTIME initiative (Dornelas et al. 2018) represents the most important global collection of biodiversity time-series including abundance records measured in species assemblages belonging to the marine, freshwater and terrestrial environments. Yet, the powerful spatial representation of BioTIME has considerable limitations that include: i) an often limited length and/or periodicity of the time-series, which particularly affects vegetation data (29 datasets with at least 6 data points; ii) a poor focus on vegetation and terrestrial plant biodiversity ( 96 datasets, corresponding to about $27 \%$ of the whole database). Given that a high number of ecosystem functions and services strongly depend on plants (Maestre et al. 2012; van der Plas 2019), we deem it crucial for the fields of vegetation science and ecology to be able to rely on a consistent and standardized collection of datasets including high-quality time-series measured at regular intervals and specific to plant communities.

Based on these premises, we hereby present the LOng-Term Vegetation Sampling (LOTVS) initiative, a growing global collection of vegetation time-series derived from the regular (mostly, annual) monitoring of vascular plants in permanent plots. By promoting the use, and supporting the visibility of high-quality temporal data collected using permanent plots, LOTVS ultimately aims to provide the tools to ask relevant ecological questions across a number of taxa, ecosystems and regions. The LOTVS collection provides a platform for aggregating the currently disconnected datasets sampled around the 
world based on permanent plots. As such, researchers are welcome to contribute to and, based on a scientific proposal (see section 3.2.), use the available collection of data.

\section{Description of LOTVS}

As of April 2021, LOTVS encompasses 79 datasets (Fig. 1) for a total of 7789 vegetation time-series, collected using permanent plots that were monitored for a minimum of six, and a maximum of 99 years (first quantile: 10; mean: 17.5; median: 16; third quantile: 23 years; see Fig 2). The vast majority of LOTVS time-series has a fine-grained temporal resolution: measurements in permanent plots were taken on $10 \%$ to $100 \%$ of the temporal interval (with $100 \%$ meaning that plots were sampled at least annually; first quantile: $82.8 \%$; mean: $87.4 \%$; median: $100 \%$; third quantile: $100 \%$ ). A description of the single datasets can be found in Valencia et al. (2020; Supplementary Material). At present, LOTVS includes vegetation time-series specifically focused on herbaceous species and shrubs mostly belonging to grassland habitats, followed by mixed vegetation types (i.e. savannas and heathlands), shrublands, forest understoreys and other habitats (mostly salt marshes; Fig. 4A; see Box 1). Forest plots monitoring changes in long-term changes in tree species are, at the moment, excluded from LOTVS (but see section Perspectives). The LOTVS collection contains data from five continents (Fig. 1; but see here for an interactive map), although Europe and North America are so far the most represented areas. While Europe is the leading continent in terms of datasets (38 out of 79), North America hosts the majority of plots (almost 70\%, distributed across 30 datasets).

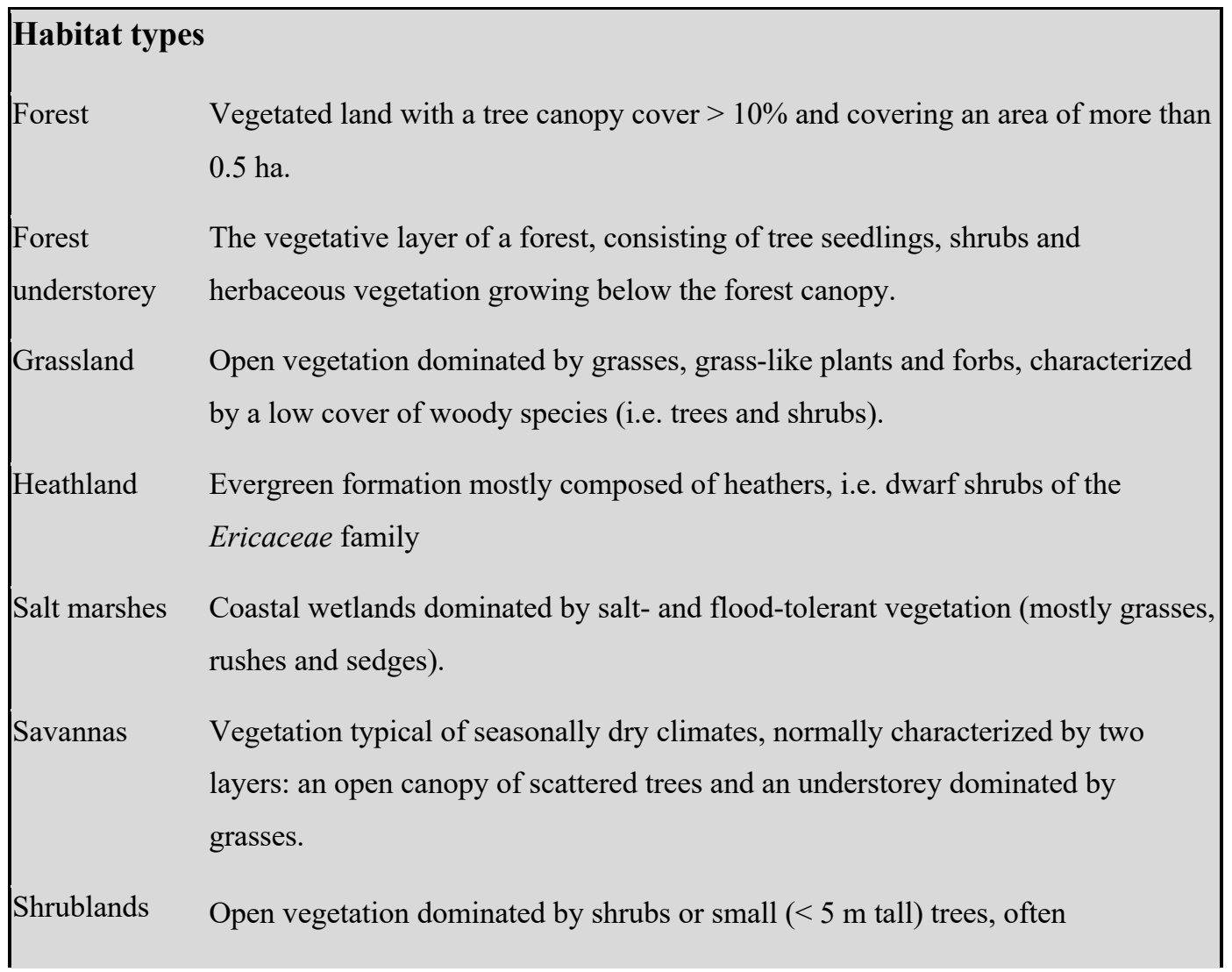


characterized by a single canopy layer.

\begin{tabular}{|c|c|}
\hline \multicolumn{2}{|c|}{ Sampling method } \\
\hline Biomass & $\begin{array}{l}\text { Clipping, drying and weighing the phytomass present in a sampling unit (either as } \\
\text { a whole or separately for each species). }\end{array}$ \\
\hline Cover & $\begin{array}{l}\text { Visual estimation of plant species cover in percentage }(\%) \text { or through the use of } \\
\text { cover classes. }\end{array}$ \\
\hline Frequency & $\begin{array}{l}\text { Estimation of species abundance based on recording the percentage of sub-units } \\
\text { occupied by each species in a certain sampling unit. This can be done, e.g. by } \\
\text { counting the number of contacts between each species and a pin. }\end{array}$ \\
\hline
\end{tabular}

74 Box 1. Working definitions of the main habitat types and sampling methods mentioned. Habitat 75 definitions were adapted from the Convention of Biological Diversity website 76 (https://www.cbd.int/forest/definitions.shtml and https://www.cbd.int/drylands/definitions), and from 77 Goldstein \& DellaSala (2020).

78 Datasets included in LOTVS span a wide climatic gradient, their mean annual temperature ranging 79 between -11.5 and $20.1^{\circ} \mathrm{C}$, and their mean annual precipitation between 14 and $259.2 \mathrm{~cm}$ (source: 80 WordClim 2; Fick \& Hijmans 2017). As such, they are mostly included in the temperate seasonal forest, 81 temperate grassland/desert and in the woodland/shrubland biomes (sensu Whittaker 1975; see Fig 3). 

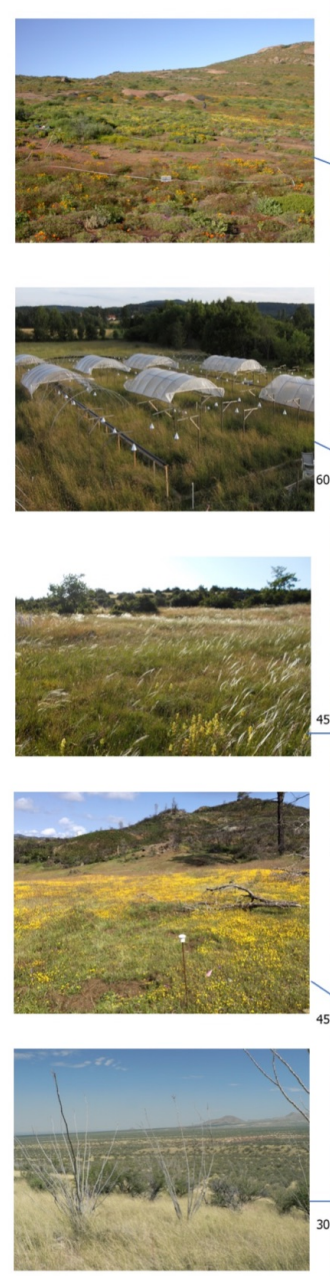

82

83

84

85

86

87

88
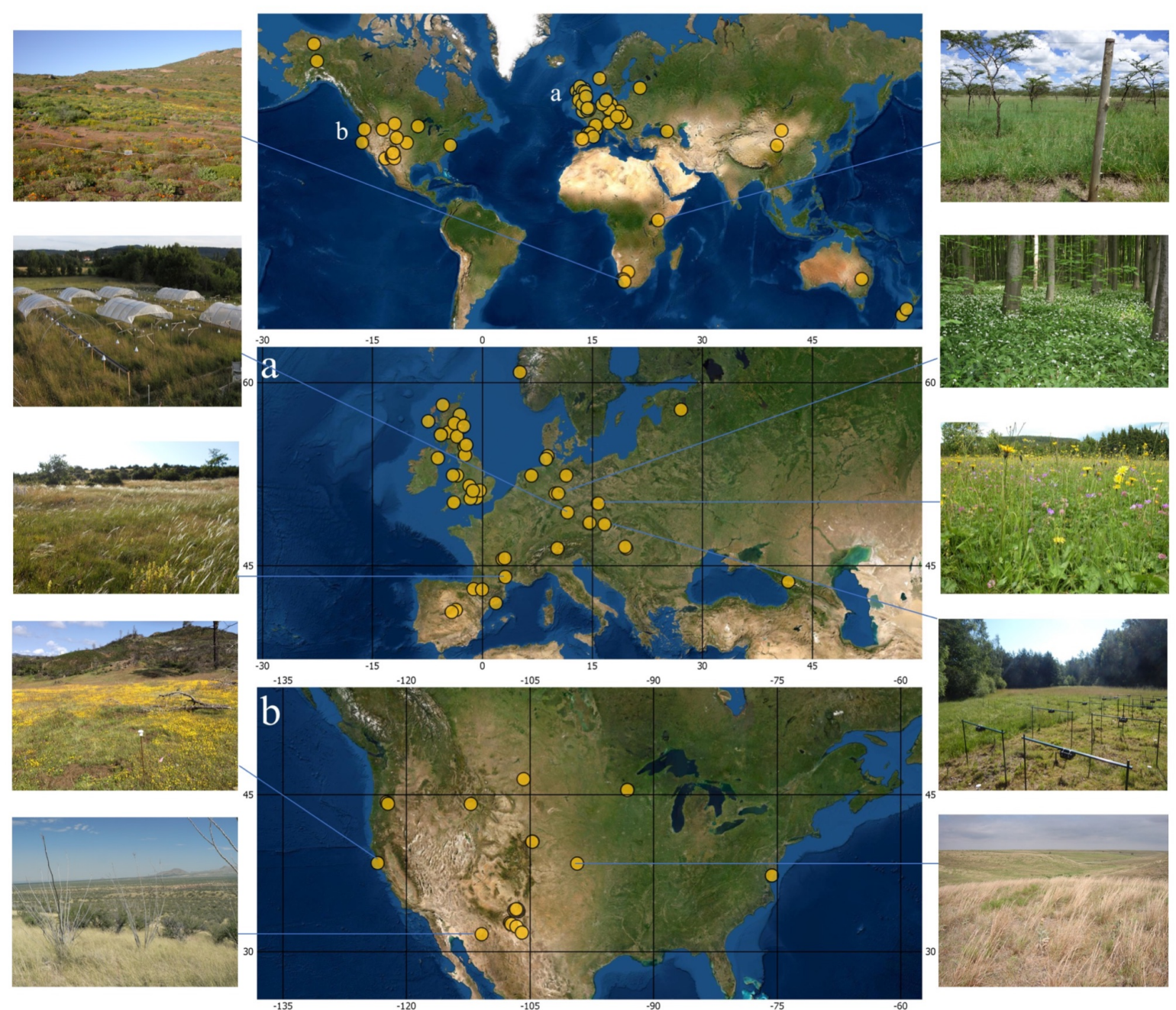

Fig. 1. Map showing the geographical location of the 79 datasets included in LOTVS. A more detailed view is given for areas featuring a high density of datasets: a) Europe; b) North America. ESRI World Satellite Imagery was used as the base map. For a subset of sites, representative vegetation types are shown. Photos were taken at: (left, starting from the top): Soebatsfontein (South Africa), Bayreuth (Germany), Roquefort-sur-Soulzon (France), California (USA), Arizona (USA); (right, starting from the top): Laikipia (Kenya), Göttinger Wald (Germany), Krkonose Mountains (Czech Republic), Ohrazeni (Czech Republic), Kansas (USA). 


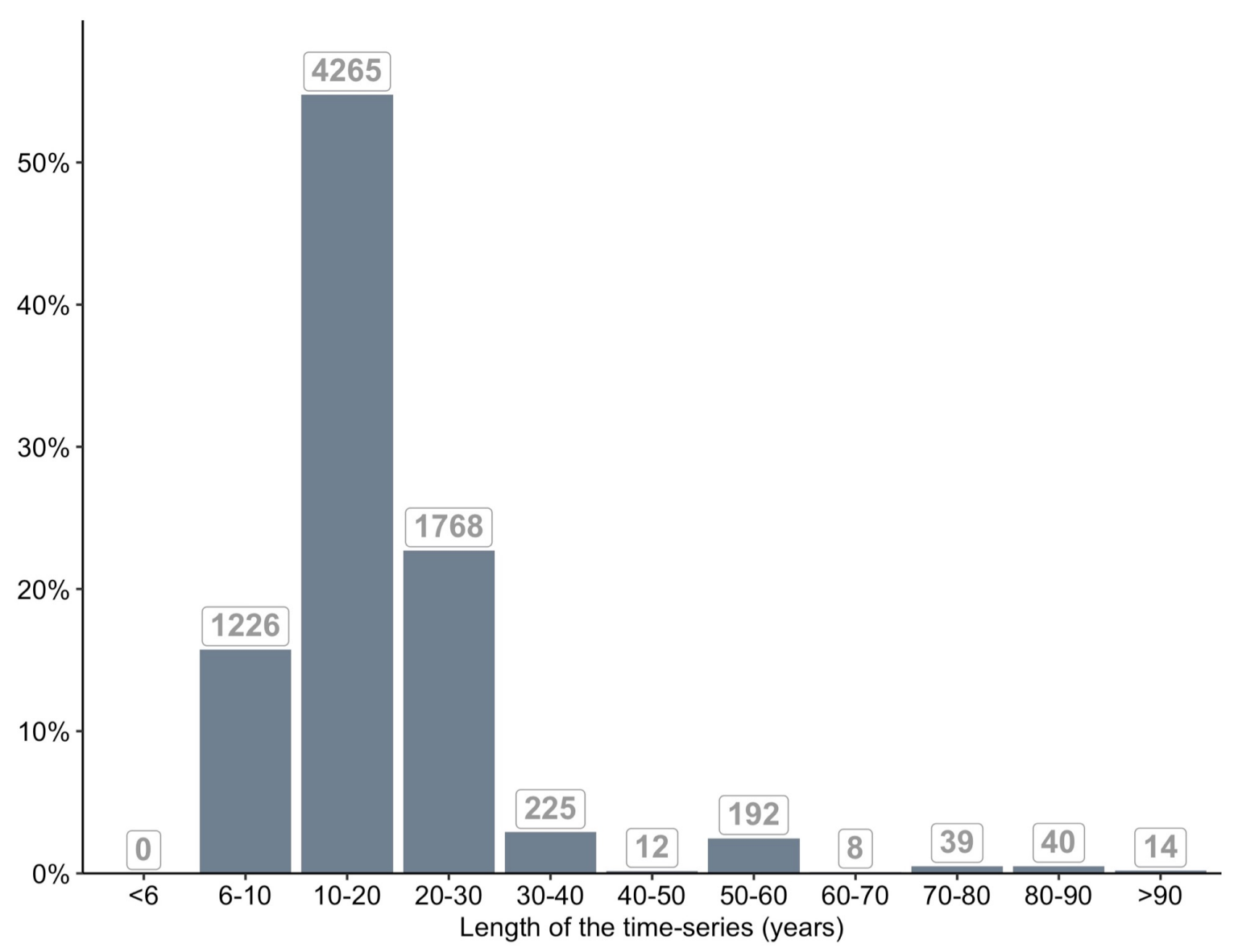
Length of the time-series (years)

97 Fig. 2. Distribution of the duration (in years) of the time-series included in LOTVS. The number of time98 series within each class is reported above the bars. 


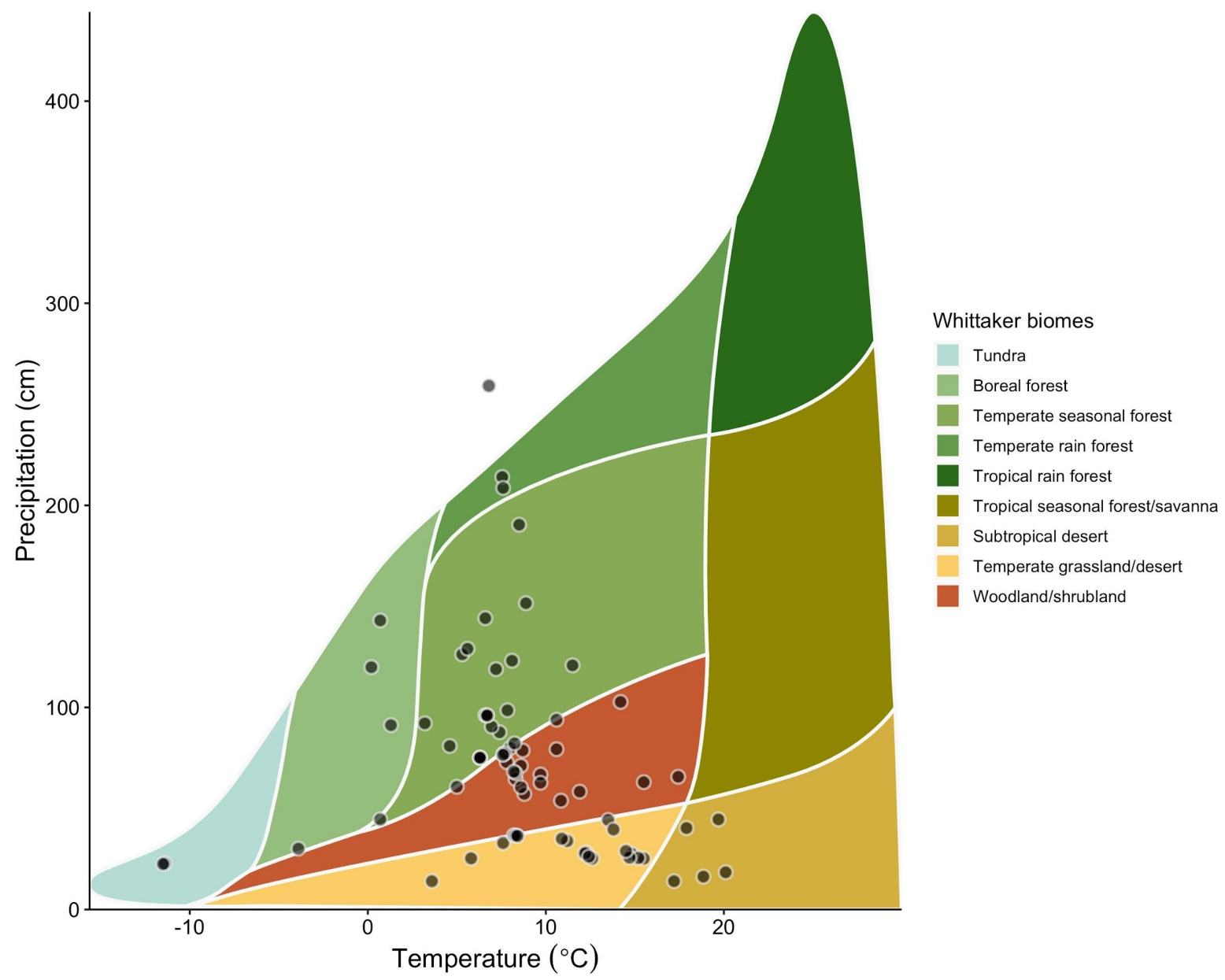

Fig. 3. Climatic summary of the 79 datasets included in LOTVS. Mean annual temperature and mean

102 annual precipitation are plotted on the $x$ and $y$ axes, respectively. Each dot represents mean climatic conditions characterizing each dataset. Dots are superimposed on Whittaker biomes (i.e. indicating potential vegetation; Whittaker, 1975), as redrawn from Ricklefs (2008). The plot was created using the R package "plotbiomes" (Stefan and Levin 2021). 
A

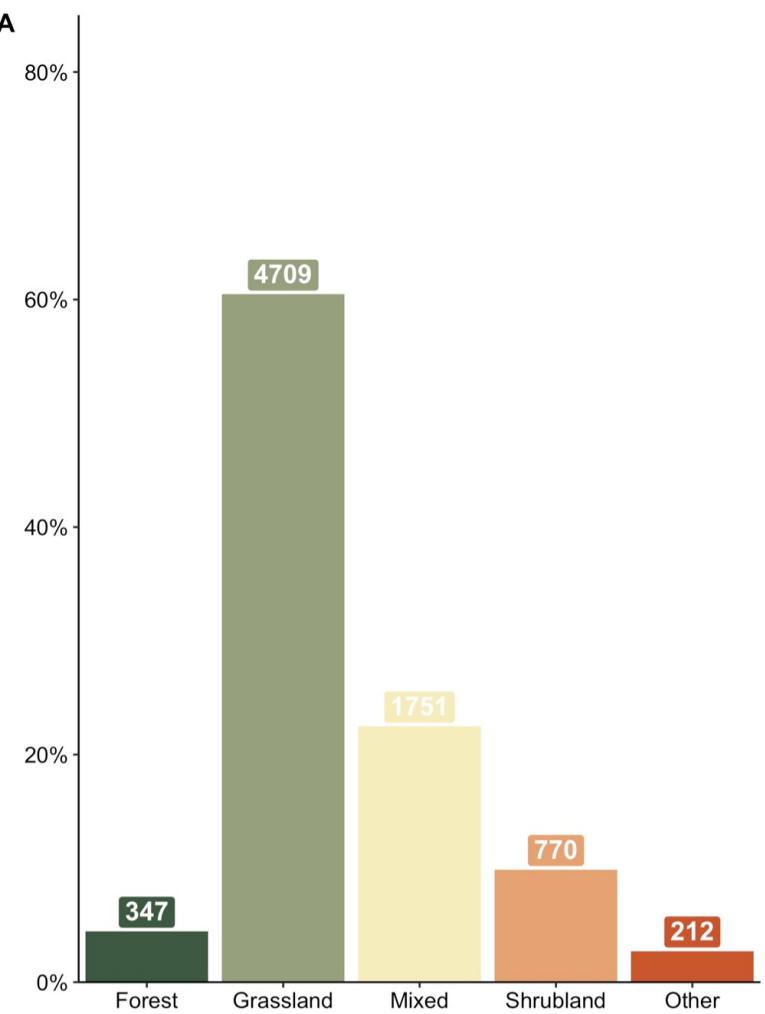

B

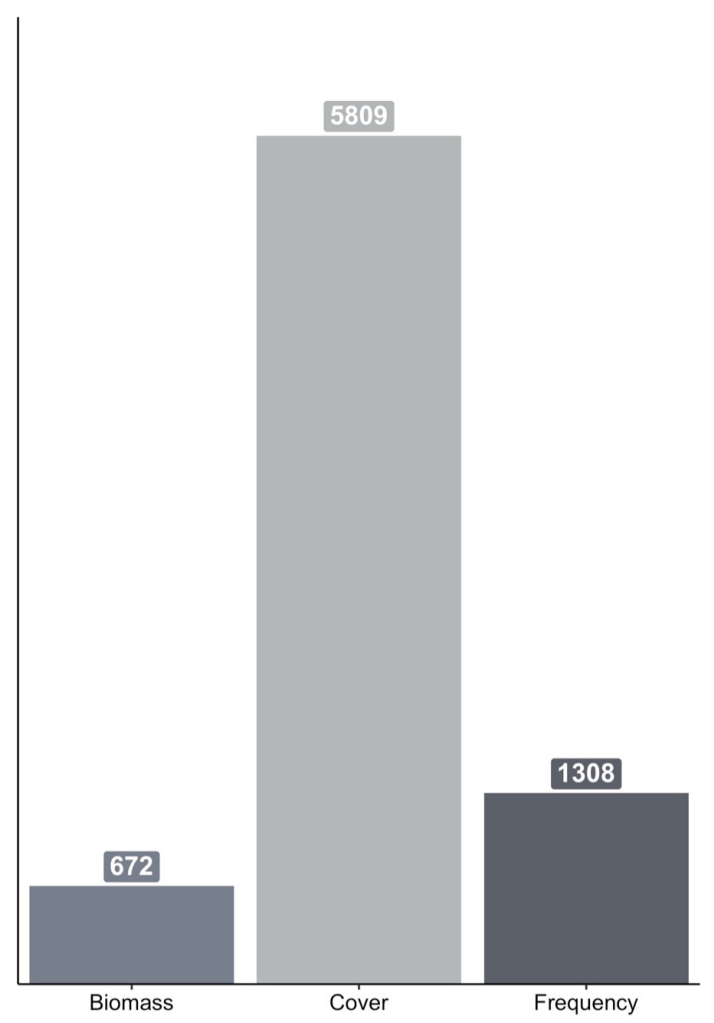

Fig. 4. Habitat types (A) and sampling methods/approaches (B) covered in LOTVS. The number of timeseries within each class is reported on top of the bars. See Box 1 for working definitions of habitat type and sampling methods.

In almost half of the permanent plots included in LOTVS (48.5\%), vegetation has been subjected to experimental treatments manipulating abiotic or biotic conditions. The most frequent treatment types are herbivore exclusion, fertilization and grazing intensification (applied to $\sim 35,24$ and $17 \%$ of the treated plots, respectively; Fig. 5). Yet, even in the absence of such treatments, LOTVS includes plots subjected to management regimes, such as mowing or grazing, that are necessary to maintain traditional land-use in given habitats. It should be noted that in 30 datasets (corresponding to about $50 \%$ of the datasets within LOTVS) traditional management was maintained as a control comparison to novel treatments.

Permanent plots in the LOTVS collection are surveyed using different techniques. The vast majority $(\sim 85 \%)$ are quadrat plots, but line transects and quadrat plots arranged along a transect are also present. Plot size ranges from 0.04 to $400 \mathrm{~m}^{2} ; \sim 80 \%$ of the plots range from 0.04 to $1.25 \mathrm{~m}^{2}$, with $1 \mathrm{~m}^{2}$ being the most frequent (49\%) plot size in the collection. Information on plot size is missing for 90 plots, corresponding to $0.8 \%$ of the whole LOTVS collection. The method used to quantify species abundance also varies among the 79 datasets (Fig. 4B). The most frequent approach uses visual estimation of species cover (75\%) followed by recording the frequency of individual species across a given number of subplots (17\%) and third by the collection of aboveground biomass for each species in the plot (9\%). 
In most cases, biomass clipping is intended to mimic mowing. All plots included in LOTVS were permanently marked in the field; geographic coordinates are available for either specific plots or for unique localities of each dataset. Besides estimating plant species abundance, some of the datasets within LOTVS originally included information about bare ground cover or the abundance of other taxa (e.g. bryophytes, lichens). However, in an effort to provide a standardized and consistent tool, this information was removed from individual datasets so that recorded taxa within LOTVS now only include vascular plants.

Taxonomic standardization is fundamental when compiling vegetation databases. On the one hand, it is a necessary step to addressing the issue of nomenclature redundancy caused by the multitude of synonyms characterizing botanical literature (Kalwij 2012); on the other hand, it allows a later integration of data with ancillary information linked to taxonomic entities, e.g. species functional traits. Original datasets included in LOTVS show considerable variation in the chosen taxonomical references reflecting different regional and national traditions as well as the time when the work was undertaken. As such, a taxonomic standardization was deemed necessary. To do this, we standardized the nomenclature of plant species following The Plant List, currently the most widely used global reference list (Kalwij 2012). This was done in R (R Core Team 2019) using the package "Taxonstand" (Cayuela et al. 2019), which allows the automatic standardization of plant names by running an internal query to The Plant List (http://www.theplantlist.org) and returning standardized species names, eventually resolving synonyms and homogenizing intraspecific taxonomic entities to the level of species.

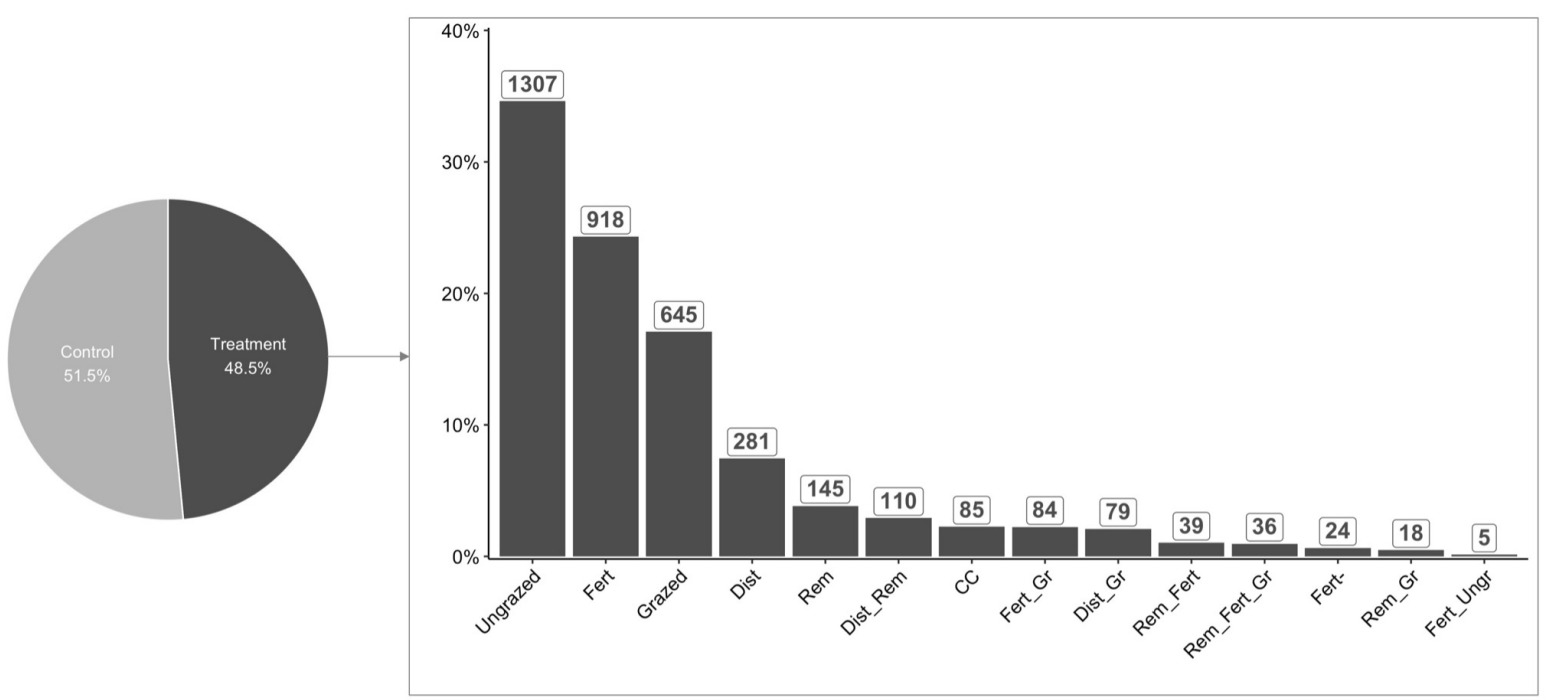

Fig. 5. Left: pie chart describing the distribution of permanent plots included in the LOTVS collection according to the absence ("control") or presence ("treatment") of treatment. Right: distribution of the type of treatments present in LOTVS. The number of time-series within each treatment is reported on top of the bars. Names for the treatments were abbreviated as follows: "Ungrazed": grazing exclosure; 
"Fert": fertilization; "Grazed": grazing; "Dist": disturbance; "Rem": removal; "Dist_Rem": disturbance + removal; "CC": climate change; "Fert_Gr": fertilization + grazing; "Dist_Gr": disturbance + grazing; "Rem_Fert": removal + fertilization; "Rem_Fert_Gr": removal + fertilization + grazing; "Fert-": decrease of productivity; "Rem_Gr": removal + grazing; "Fert_Ungr": fertilization + grazing exclosures.

\section{Data usage}

As an unprecedented collection of vegetation time-series, LOTVS has a huge potential to support groundbreaking research in the fields of vegetation science, plant ecology and temporal ecology. It should be noted, though, that installing and maintaining permanent plots is a very time- and resourceconsuming task, and thus a powerful collection of vegetation plots such as LOTVS can only arise from collaborative efforts that stem from an impressive amount of work carried out by many data contributors, whose effort must be acknowledged. To this end, anyone can contribute to LOTVS with original data, as long as the data fully comply with LOTVS requirements (see section 3.2.). At the same time, data included in LOTVS can be requested and used following a simple procedure that is intended to maximize transparency and support well-grounded research projects.

\subsection{Contributing data}

Detailed information on how to contribute to LOTVS, as well as specific data requirements can be found on the dedicated website https://lotvs.csic.es/contribute/. LOTVS welcomes datasets including vegetation time-series collected from permanent plots with a fixed (i.e. permanently marked) geographical position in the field, possibly replicated in space, maintained for a minimum of 6 years and sampled at regular (preferably annual) intervals. In principle, the time-series should be continuous, i.e. gaps should not be present. However, exceptions are allowed, provided that observations for some years are only missing for a reduced number of plots. In cases of missing years for all of the permanent plots, the new dataset can only be incorporated to LOTVS if a) only a very limited number of years is missing and b) their distribution within the time-series is irregular, i.e. LOTVS is not intended to accept permanent plots that, according to their original scope, are only sampled every $n$ years. Following these requirements, we are also not looking to include data collected in the context of so-called resurveying studies, where historic vegetation plots are revisited after a longer time period and re-recorded. In fact, these are the subject of other databases (e.g. the ReSurveyEurope initiative, http://euroveg.org/evadatabase-re-survey-europe). Also, whereas data collected using different sampling approaches are welcomed (e.g. visual estimation of species cover, biomass, frequency, number of individuals), the sampling approach should be as consistent as possible over time. LOTVS does not plan, at present, to incorporate permanent plots that only record species occurrence (i.e. presence/absence data). To be included in LOTVS, permanent plots should be preferably representative of natural or semi-natural 
vegetation. The former can be defined as vegetation that developed in absence of human influence and/or has long been left undisturbed by humans; as to the latter, its existence and maintenance depend on human practices (e.g. grazing, mowing) carried out for either production, conservation, or a mix of the two purposes. As such, time-series data recorded from artificial seed mixtures such as those sown in biodiversity experiments are not currently accepted.

\subsection{Requesting data}

Because of the effort needed to maintain permanent plots in time and collect temporal vegetation data (Mills et al. 2015), access to individual time-series or datasets included in LOTVS is governed by a data policy that allows data owners and contributors to remain in full control of their data if they so choose (see https://lotvs.csic.es/contribute/ for detailed information). The availability and access of single datasets depend on the choice of individual data owners and contributors, who decide the accessibility level of their data (from "restricted data", i.e. data are only usable upon consent from data owners/contributors, that should be expressed each time their dataset is requested; to "free data" i.e. data that are freely available to use through the LOTVS platform). We note that about $40 \%$ of LOTVS datasets are publicly available, either because they belong to Long-Term Ecological Research (LTER) Programs, or because they were archived and published by their data owners. Also, several of the LOTVS datasets are publicly available in their own right, via contact with their owners. Depending on the accessibility level specified, data owners and contributors hold (or not, in case of freely usable data) the right to request authorship on eventual publications based on the proposal submitted by the applicants when they request the data. In all cases, to request data included in LOTVS, a short and sound scientific proposal describing the aims of the project and the type of data required should be prepared and submitted to the LOTVS' Supervising Committee. This process is intended to i) minimize conceptual overlap of proposals addressing highly similar research questions and ii) make sure that all data owners are informed about the possible use of their data and are free to decline it if they wish so.

\section{Perspectives}

In its present form, LOTVS includes vegetation time-series for almost 8000 permanent plots installed and maintained in natural and semi-natural plant communities worldwide. Still, as we explained in section 2, the geographical representation of both individual datasets and permanent plots is not homogeneous; it is biased towards Europe and North America, and many habitats, such as forest habitats, are strongly underrepresented. In order to promote a more equal representation in terms of geographical areas and habitats, one of the goals of this paper is to encourage new datasets including time-series recorded using permanent plots located in currently underrepresented continents such as Africa, Asia, Australia and South America. Similarly, time-series recorded in forests, tundra and coastal areas would be particularly welcome. Concerning forests, it should be noted that in its current version 
223 LOTVS only includes permanent plots located in the understory layer, while we look forward to 224 increasing the representation of actual forest time-series. Furthermore, we are very interested in datasets 225 featuring spatial as well as temporal replication (minimum 6 years as mentioned above) to disentangle 226 the differences between temporal and spatial changes. Finally, to broaden the range of potential 227 applications of LOTVS (and in line with what has been done by other global initiatives, see Bruelheide 228 et al. 2019), we are planning to integrate it with information on environmental variables (climate, micro229 climate) and species functional traits. Such integration will eventually allow users direct access to 230 ancillary data crucial to explore the evolution of different facets of diversity over time (Monnet et al. 231 2014; Sperandii et al. 2021).

\section{Conclusions}

233 LOTVS possibly represents the largest collection of temporally fine-grained vegetation time-series made accessible to the research community derived from permanent plots addressing the study of plant communities through time. As such, LOTVS can be highly useful to perform timely research on a wide range of topics in the field of vegetation science: investigating patterns and drivers of ecological succession in natural plant communities, quantifying vegetation changes through time, as well as assessing community stability and identifying its mechanisms. At the same time, because it includes a considerable proportion of permanent plots subjected to some kind of treatment (e.g. grazing, fertilization etc.), LOTVS can also support the development of large-scale studies aiming to understand how temporal dynamics are affected by different treatments in the context of global changes. Last, but not least, we believe LOTVS could also serve as a valuable resource to conduct methodological research addressing topics related to, for example, methods to quantify dissimilarity through time and their partitioning (Baselga 2010; Legendre \& Condit 2015) or quantitative approaches to investigate community dynamics and more specifically, stability.

\section{Funding information}

247 Nicola J. Day was funded by the Rutherford Postdoctoral Fellowship from Te Apārangi Royal Society

248 of New Zealand. Francesco de Bello was supported by the Spanish Plan Nacional de I+D+i (project 249 PGC2018-099027-B-I00). Eric Garnier acknowledges support from La Fage INRA experimental station. Tomáš Herben was funded through the GAČR grant 20-02901S. Anke Jentsch was supported by the German Federal Ministry of Education and Research (BMBF) with the grant 031B0516C (SUSALPS), and by the Oberfrankenstiftung with the grant OFS FP00237. Norbert Juergens was

253 funded by the German Federal Ministry of Education and Research (BMBF) through the grant 254 01LG1201N (SASSCAL ABC). Frédérique Louault and Katja Klumpp acknowledge support from the AnaEE-France (ANR-11-INBS-0001) in natura SOERE-ACBB permanent grassland sites of Theix and 
257

258

259

260

261

262

263

264

265

266

267

268

269

270

271

272

273

274

275

276

277

278

279

280

281

282

283

284

285

286

287

288

289

290

Government's Rural and Environment Science and Analytical Services Division. Meelis Pärtel acknowledges support by the Estonian Research Council (PRG609) and by the European Regional Development Fund (Centre of Excellence EcolChange). Josep Peñuelas was supported by the Spanish Government (grant PID2019-110521GB-I00), the Fundación Ramon Areces (grant ELEMENTALCLIMATE), the Catalan Government (grant SGR 2017-1005), and the European Research Council (Synergy grant ERC-SyG-2013-610028, IMBALANCE-P). Ute Schmiedel was funded by the German Federal Ministry of Education and Research (Promotion numbers 01LC0024, 01LC0024A, 01LC0624A2, 01LG1201A, 01LG1201N). Hana Skálová received financial support through the GAČR grant 20-02901S. Karsten Wesche acknowledges support from the International Institute Zittau, Technische Universität Dresden, Dresden, Germany. Susan K. Wiser was funded by the New Zealand Ministry for Business, Innovation and Employment's Strategic Science Investment Fund. Ben A. Woodcock was funded by NERC and BBSRC (NE/N018125/1 LTS-M ASSIST - Achieving Sustainable Agricultural Systems). Enrique Valencia was funded by the 2017 program for attracting and retaining talent of Comunidad de Madrid ( $\mathrm{n}^{\circ}$ 2017-T2/AMB-5406). Truman P. Young acknowledges support from the National Science Foundation (LTREB DEB 19-31224).

\section{References}

Bakker, J. P., Olff, H., Willems, J. H., \& Zobel, M. 1996. Why do we need permanent plots in the study of long-term vegetation dynamics? Journal of Vegetation Science 7(2): 147-156.

Baselga, A. 2010. Partitioning the turnover and nestedness components of beta diversity. Global Ecology and Biogeography 19(1): 134-143.

Bernhardt-Römermann, M., Baeten, L., Craven, D., De Frenne, P., Hédl, R., Lenoir, J., ... \& Verheyen, K. 2015. Drivers of temporal changes in temperate forest plant diversity vary across spatial scales. Global Change Biology 21(10): 3726-3737.

Blowes, S. A., Supp, S. R., Antão, L. H., Bates, A., Bruelheide, H., Chase, J. M., ... \& Dornelas, M. 2019. The geography of biodiversity change in marine and terrestrial assemblages. Science 366(6463): 339-345.

Bradshaw, C. J., Ehrlich, P. R., Beattie, A., Ceballos, G., Crist, E., Diamond, J., ... \& Blumstein, D. T. 2021. Underestimating the challenges of avoiding a ghastly future. Frontiers in Conservation Science: $1-9$. 
291 Brondizio E.S., Settele J., Díaz S., \& Ngo H.T.(Eds.). 2019. IPBES: Global assessment report on 292 biodiversity and ecosystem services of the Intergovernmental Science Policy Platform on Biodiversity and Ecosystem Services. Bonn, Germany: IPBES Secretariat.

294

295 Bruelheide, H., Dengler, J., Jiménez-Alfaro, B., Purschke, O., Hennekens, S. M., Chytrý, M., ... \& Tang, 296 Z. 2019. sPlot-A new tool for global vegetation analyses. Journal of Vegetation Science 30(2): 161297186.

298

299 Cayuela, L., Macarro, I., Stein, A. and Oksanen, J. 2019. Taxonstand: Taxonomic Standardization of 300 Plant Species Names. R package version 2.2. https://CRAN.R-project.org/package=Taxonstand.

301 Ceballos G., Ehrlich P.R., Barnosky A.D., García A., Pringle R.M., \& Palmer T.M. 2015. Accelerated 302 modern human-induced species losses: Entering the sixth mass extinction. Science Advances 1(5): e1400253.

304 Chytrý M., Hennekens S.M., Jiménez-Alfaro B., Knollová I., Dengler J., Jansen F., ... \& Yamalov S. 305 2016. European Vegetation Archive (EVA): an integrated database of European vegetation plots. 306 Applied Vegetation Science 19(1): 173-180.

307 Chytrý M., Chiarucci A., Pärtel M. and Pillar V.D. 2019. Progress in vegetation science: trends over the past three decades and new horizons. Journal of Vegetation Science 30: 1-4.

309 Convention on Biological Diversity. 2020. Global Biodiversity Outlook. Montréal, QC: Secretariat of 310 the Convention on Biological Diversity.

311 Damgaard C. 2019. A critique of the space-for-time substitution practice in community ecology. Trends 312 in Ecology \& Evolution 34: 416-421.

313 de Bello F., Valencia E., Ward D., \& Hallett L. 2020. Why we still need permanent plots for vegetation 314 science. Journal of Vegetation Science 31(5): 679-685.

315 Dengler J., Jansen F., Glöckler F., Peet R.K., De Cáceres M., Chytrý M., ... \& Spencer N. 2011. The 316 Global Index of Vegetation-Plot Databases (GIVD): a new resource for vegetation science. Journal of 317 Vegetation Science 22(4): 582-597.

318 Dornelas M., Antao L.H., Moyes F., Bates A.E., Magurran A.E., Adam D., ... \& Murphy G. 2018. 319 BioTIME: A database of biodiversity time series for the Anthropocene. Global Ecology and 320 Biogeography 27(7): 760-786. 
321 Fick S.E., \& Hijmans R.J. 2017. WorldClim 2: new 1-km spatial resolution climate surfaces for global

322 land areas. International Journal of Climatology, 37(12): 4302-4315.

323 Goldstein, M.I., \& DellaSala, D.A. 2020. Encyclopedia of the World's Biomes. Elsevier.

324 Gonzalez A., Cardinale B.J., Allington G.R., Byrnes J., Arthur Endsley K., Brown D.G., ... \& Loreau 325 M. 2016. Estimating local biodiversity change: a critique of papers claiming no net loss of local diversity. Ecology 97(8): 1949-1960.

327 Hillebrand H., Blasius B., Borer E.T., Chase J.M., Downing J.A., Eriksson B.K., ... \& Ryabov A. B. 328 2018. Biodiversity change is uncoupled from species richness trends: Consequences for conservation and monitoring. Journal of Applied Ecology 55(1): 169-184. term dynamics in grassland communities. Ecology Letters 20(12): 1556-1565.

332 Kalwij, J.M. (2012). Review of 'The Plant List, a working list of all plant species'. Journal of Vegetation 333 Science 23(5): 998-1002.

334 Legendre P., \& Condit R. 2019. Spatial and temporal analysis of beta diversity in the Barro Colorado 335 Island forest dynamics plot, Panama. Forest Ecosystems 6(1): 1-11.

336 Maestre F.T., Quero J.L., Gotelli N.J., Escudero A., Ochoa V., Delgado-Baquerizo M., ... \& Zaady E. 337 2012. Plant species richness and ecosystem multifunctionality in global drylands. Science 335(6065): $338 \quad 214-218$.

339 Mills J.A., Teplitsky C., Arroyo B., Charmantier A., Becker P.H., Birkhead T.R., ... \& Zedrosser A. 340 2015. Archiving primary data: solutions for long-term studies. Trends in Ecology \& Evolution 30(10): $341 \quad 581-589$.

342 Monnet A.C., Jiguet F., Meynard C.N., Mouillot D., Mouquet N., Thuiller W., \& Devictor V. 2014. 343 Asynchrony of taxonomic, functional and phylogenetic diversity in birds. Global Ecology and 344 Biogeography 23(7): 780-788.

345 Newbold T., Hudson L.N., Hill S.L., Contu S., Lysenko I., Senior R.A., ... \& Purvis A. 2015. Global 346 effects of land use on local terrestrial biodiversity. Nature 520(7545): 45-50.

347 Pereira H.M., Navarro L.M., \& Martins I.S. 2012. Global biodiversity change: the bad, the good, and 348 the unknown. Annual Review of Environment and Resources 37: 25-50. 
349 Pimm S.L., Jenkins C.N., Abell R., Brooks T. M., Gittleman J.L., Joppa L.N., ... Sexton J.O. 2014. The

350 biodiversity of species and their rates of extinction, distribution, and protection. Science 344: 987.

351 R Core Team. 2019. R: A language and environment for statistical computing. R Foundation for 352 Statistical Computing, Vienna, Austria. URL https://www.R-project.org/.

353 Ricklefs R.E. 2008. The economy of nature. Macmillan.

354 Sabatini F.M., Lenoir J., Hattab T., Arnst E., Chytrý M., Dengler J., ... Bruelheide H. 2021. sPlotOpen

355 - An environmentally-balanced, open-access, global dataset of vegetation plots. Global Ecology and 356 Biogeography. https://doi.org/10.1111/geb.13346.

357 Sperandii M.G., Barták V., Carboni M., \& Acosta A.T.R. 2021. Getting the measure of the biodiversity 358 crisis in Mediterranean coastal habitats. Journal of Ecology 109(3): 1224-1235.

359 Stefan V. and Levin S. 2021. plotbiomes: Plot Whittaker biomes with ggplot2. R package version $360 \quad 0.0 .0 .9001$.

361 Valencia E., de Bello F., Galland T., Adler P.B., Lepš J., E-Vojtkó A.., ... \& Götzenberger L. 2020. 362 Synchrony matters more than species richness in plant community stability at a global scale.

363 Proceedings of the National Academy of Sciences 117(39): 24345-24351.

364 van der Plas F. 2019. Biodiversity and ecosystem functioning in naturally assembled communities.

365 Biological Reviews 94(4): 1220-1245.

366 Verheyen K., Bažány M., Chećko E., Chudomelová M., Closset-Kopp D., Czortek P., ... \& Baeten, L. 367 2018. Observer and relocation errors matter in resurveys of historical vegetation plots. Journal of 368 Vegetation Science 29(5): 812-823.

369 Whittaker R.H. 1975. Communities and Ecosystems, 2nd ed., Macmillan, New York .

370 Wiser S.K. 2016. Achievements and challenges in the integration, reuse and synthesis of vegetation plot 371 data. Journal of Vegetation Science 27(5): 868-879. 